\title{
Clinical outcomes and technical description of unstented end to side pancreaticogastrostomy by small posterior gastrotomy
}

\author{
Sandeep Kumar Bhoriwal, Sunil Kumar, SVS Deo, Jyoti Sharma, \\ Ashutosh Mishra, Naveen Kumar, Jyoutishman Saikia, and Kunal Dhall \\ Department of Surgical Oncology, All India Institute of Medical Science, New Delhi, India
}

\begin{abstract}
Backgrounds/Aims: Morbidity following Whipple's surgery largely depends upon the pancreatic stump anastomosis leak. Pancreaticogastrostomy is one of the techniques of pancreatic stump reconstruction and is described variously in the literature. Duct to mucosa pancreaticogastrostomy is described either by a large 3-4 cm posterior gastrotomy or by small gastrotomy of 2-3 mm with the use of internal stents along with. We describe clinical outcomes and technique of 2 layer end to side pancreatico-gastrostomy by a small posterior gastrotomy without the use of internal stents. Methods: Hospital records of 35 patients where the technique of, small posterior gastrotomy end to side duct to mucosa pancreatico-gastrostomy without internal stents, was used for pancreatic stump reconstruction were studied retrospectively. The data were analyzed for demographic details, stage of the disease, and short term outcomes related to surgical procedure. Results: The mean duration of surgery was 7.4 hours. Grade A, B, and C POPF were observed in $10(28.5 \%), 3(8.5 \%)$, and $1(2.8 \%)$ of patients respectively. The mean time to remove pancreatic drain was 9 days, and the mean time to start oral feeds was 8.9 days. The mean hospital stay was 12.9 days (07-26). Thirty days mortality was $2.8 \%$. Conclusions: Unstented duct to mucosa end to side pancreatico-gastrostomy technique is comparable with other pancreatico-gastrostomy techniques in outcomes in terms of POPF, morbidity, mortality, and hospital stay. However, to establish the superiority or inferiority of this technique, a larger study is recommended. (Ann Hepatobiliary Pancreat Surg 2021;25:251-258)
\end{abstract}

Key Words: Pancreatic cancer; Pancreaticoduodenectomy; Pancreatic fistula

\section{INTRODUCTION}

Pancreatic cancer is the $11^{\text {th }}$ most common cancer worldwide and as per GLOBOCAN 2018, 355,317 new cases will be diagnosed until 2040. Pancreatic cancer is a lethal malignancy and is the seventh leading cause of mortality in cancer patients. Despite the new diagnostic and treatment modalities, 5year survival is $9 \%$ only. ${ }^{1,2}$

Pancreas cancer is treated with multimodality treatment however surgery is the mainstay of treatment. Pancreaticoduodenectomy for the pancreatic tumor is anatomically challenging and technically difficult and requires expertise. The most challenging part of the surgery is pancreatic anastomosis as any disruption in it can cause post-operative morbidity as well as mortality. The fate of anastomosis depends upon several factors i.e. patients related factors, the texture of the pancreas, duct size, technique of pancreatic anastomosis, and experience of the surgeon.

In the literature, various techniques of pancreatic anastomosis have been described after Pancreaticoduodenectomy. The anastomosis of the remaining pancreas is usually done with jejunum or stomach and both have their advantages. However, pancreaticogastrostomy has multiple reasons to be favored over pancreaticojejunostomy. ${ }^{3}$ Different techniques are described for pancreatico-gastrostomy i.e. dunking, duct to the mucosa, double purse-string technique, and Peng Binding technique, etc. These techniques are tried globally to decrease pancreatic stump complications like POPF. Duct to mucosa technique either utilizes 2 to $3 \mathrm{~cm}$ gastrotomy in the posterior wall to invaginate the pancreas into the stomach or a $2-3 \mathrm{~mm}$ smaller gastrotomy where the anastomosis is done over a stent. In this

Received: July 29, 2020; Revised: November 12, 2020; Accepted: November 13, 2020

Corresponding author: Sandeep Kumar Bhoriwal

Department of Surgical Oncology, All India Institute of Medical Science, New Delhi 110029, India Tel: +91-11-2957-5202, Fax:+91-9811104423, E-mail: drsandeepbhoriwal@gmail.com

Copyright (C) 2021 by The Korean Association of Hepato-Biliary-Pancreatic Surgery

This is an Open Access article distributed under the terms of the Creative Commons Attribution Non-Commercial License (http://creativecommons.org/ licenses/by-nc/4.0) which permits unrestricted non-commercial use, distribution, and reproduction in any medium, provided the original work is properly cited. Annals of Hepato-Biliary-Pancreatic Surgery • pISSN: 2508-5778 - elSSN: 2508-5859 
study, we have described the postoperative outcomes and technique of pancreaticogastrostomy where a 2 layer end to side duct to mucosa anastomosis is done between the pancreatic duct and gastric mucosa with 2 to $3 \mathrm{~mm}$ posterior gastrotomy without a stent. To best our knowledge, this is the first study showing postoperative outcomes of unstented small incision duct to mucosa pancreaticogastrostomy.

\section{MATERIALS AND METHODS}

Records of 35 patients, who underwent Whipple's procedure at the department of surgical oncology at a tertiary care cancer hospital from November 2015 to February 2020, where pancreatic reconstruction was done a by 2 layered pancreaticogastrostomy, were analyzed. All patients were evaluated in a multidisciplinary gastrointestinal cancer clinic and diagnosed as either peri-ampullary cancer, head of pancreas cancer, or distal cholangiocarcinoma. Triple phase contrast-enhanced computed tomography was done as per pancreatic protocol to stage the disease and assess the operability. Biliary drainage either by endoscopic retrograde cholangiopancreatography (ERCP) and stenting or percutaneous transhepatic biliary drainage (PTBD) was performed in patients where the bilirubin level was more than $14 \mathrm{mg} / \mathrm{dl}$. All surgically operable patients were taken for surgery and classical Whipple's procedure was done either by open method or assisted by laparoscopy. In the minimally invasive method, the mobilization was done laparoscopically while specimen retrieval and reconstruction were done by the open method through a small incision in the midline that was also used to retrieve the specimen. Choledochojejunostomy and gastrojejunostomy were made either by Roux-loop or by a single loop of jejunum. Pancreatic stump reconstruction was done by pancreaticogastrostomy. Darin and serum amylase were checked on the third postoperative day. The postoperative pancreatic fistula was defined as per the International study group (ISGPF) definition. ${ }^{4}$ Data for postoperative outcomes were analyzed and compared with other pancreaticogastrostomy techniques.

\section{Surgical technique of 2 layer end to side duct to mucosa pancreaticogastrostomy}

The pictorial diagram of surgical technique is described in Fig. 1. The division of the pancreas was done at the level of the neck. The stump of the pancreas was prepared for $3 \mathrm{~cm}$ distally by clearing off the soft tissue. The pancreatic duct was prepared by dilating it with boogie so that the minimum diameter of the duct becomes $2 \mathrm{~mm}$. Six absorbable 4-0 single-armed, round-bodied sutures (however double-armed suture is preferred) were taken from the anterior serosal surface of the pancreas, taken out from the cut surface of the pancreas, held by hemostats, and numbered by spreading them in order over a surgical mop. This constitutes the anterior part of the first sero-parenchymal layer. Similarly, 3 to 5 absorbable 4-0 sutures passed through the cut surface of the pancreas near and anterior to the duct, taken out from the lumen of the duct, (Outside-in) held and numbered. This constituted the anterior part of the second layer. One to three $4 / 0$ sutured were passed from the lumen of the duct, through the posterior wall of the duct and were taken out from the cut surface of the pancreas and numbered (Inside-out). This constitutes the posterior part of the second layer. The next 5 sutures were passed from the cut surface of the pancreas and were taken out through the posterior surface of the pancreas. This constitutes the posterior part of the first layers sutures. The numbering helps in the proper orientation of the sutures in various layers. The greater curvature of the stomach is flipped anteriorly and superiorly to expose the posterior surface. Appropriate site of approximation of the pancreas to the posterior surface of the stomach, which is directly falling over the pancreatic stump without traction, is identified and posterior first layer sutures are passed through the posterior wall of the stomach in the sero-muscular plane and tied. This completes the posterior first layer. A small gastrotomy of the size of the duct is made in the posterior wall of the stomach by diathermy ensuring complete hemostasis. Sutures of the posterior second layer are now passed from the serosal surface of the stomach full thickness into the lumen and taken out from the lumen of the gastrotomy site and tied (Outside-in). Sutures of the anterior second layer are now passed through the gastrotomy from the mucosal surface of the stomach, passed through the full-thickness lumen, and taken out from the serosal side and tied (Inside-out). This completes the anterior part of the second layer. Finally, the sutures from the anterior first layer are passed in the sero-muscular plane of the 
A

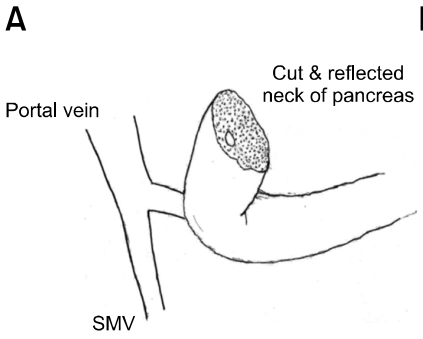

B

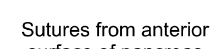
Sutures from anterior
surface of pancreas $1 / t^{2}$
C

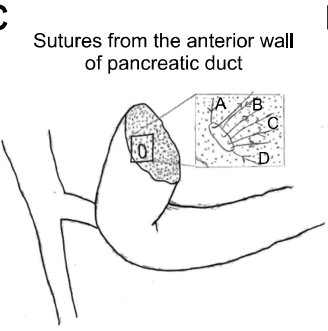

D Sutures from the posterior wall of pancreatic duct

E

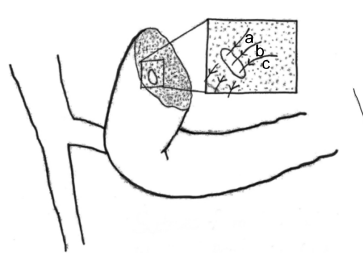

Sutures from posterior surface of pancreas
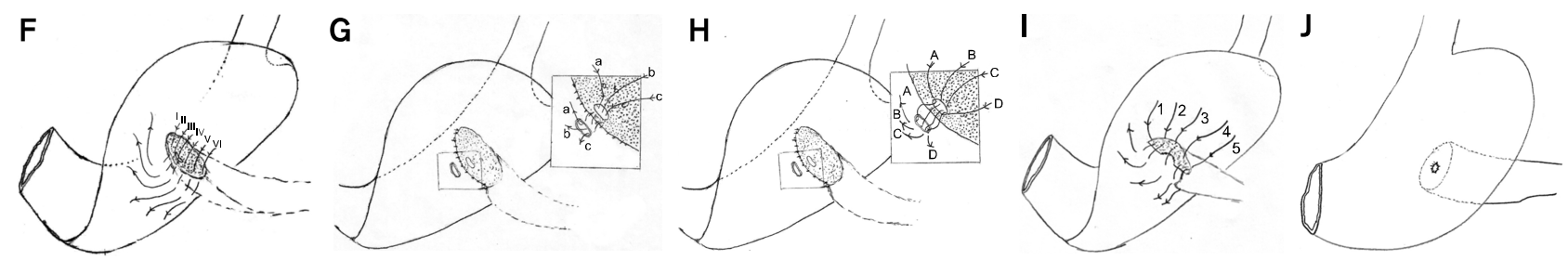

Fig. 1. Diagrammatic representation of the surgical technique. (A) Shows preparation of pancreatic stump. Approximately 2-3 $\mathrm{cm}$ of the body of the pancreas is cleared off soft tissue and veins draining to splenic veins are tied. (B) (Anterior first layer). Passing of the first layer of sutures from the anterior serosal surface of the pancreas through the cut surface of the pancreas. These are numbered and held aligned by hemostats. (C) (Anterior second layer). Passing of the second layer of sutures from the cut surface of the pancreas through the anterior wall of the pancreatic duct. These are numbered and held aligned by hemostats. (D) (Posterior second layer) passing of posterior second layer of sutures from the posterior wall of the duct through the cut surface of the pancreas. These are numbered and held aligned by hemostats. (E) (Posterior first layer) Passing of posterior first layer of sutures from the cut surface of the pancreas through the posterior serosal surface of the pancreas. These are numbered and held aligned by hemostats. (F) The greater curvature of the stomach is flipped anteriorly and superiorly. Appropriate site of approximation of the pancreas to the posterior surface of the stomach is identified and posterior first layer sutures are passed through the posterior layer of the stomach in the sero-muscular plane and tied. This completes the posterior first layer. (G) A small gastrotomy of the size of the duct is made in the posterior wall of the stomach. Sutures of the posterior second layer are now passed from the serosal surface of the stomach full thickness into the lumen and taken out from the lumen of the gastrotomy site and tied. This completes the posterior second layer. (H) Sutures of anterior second layers are now passed through the gastrotomy from the mucosal surface of the stomach full thickness and taken out from the serosal side and tied. This completes the anterior second layer. (I) Demonstrates the completed duct to mucosa anastomosis and now the sutures from the anterior first layer are passed in the sero-muscular plane of the stomach and tied. This completes the anterior first layer. (J) Shows the completed anastomosis where the only duct to mucosa anastomosis is visible in the posterior wall of the stomach.

stomach and tied. This completes the anterior first layer.

\section{RESULTS}

Thirty-five patients were included in the study. The mean age was 53.25 years (33-70) and the majority were male $(54 \%)$. The most common symptom at presentation was jaundice (83\%) followed by anorexia and weight loss. Eighty-three percent of patients had ECOG-1. The majority of the patients had peri-ampullary carcinoma $(n=31)$. Preoperative biliary drainage was required in $72 \%$ of the patients. Only one patient received neoadjuvant chemotherapy.

Open Whipple's procedure was performed in $68.5 \%$ of patients whereas $20 \%$ of the patients underwent laparoscopically assisted Whipple's procedure. Only one patient had a locally advanced tumor and required superior mesenteric vein reconstruction. The mean operative blood loss was $635 \mathrm{ml}$ and mean duration of surgery was 7.4 hours. The average duration for the duct to mucosa pancreatico-gastrostomy was $45 \mathrm{~min}$. All patients were shifted to the intensive care unit (ICU) in the post-operative period and the average ICU stay was 4.36 days (Table 1 shows the baseline characteristics of the patients).

Only one patient developed clinically significant POPF. Grade I POPF was observed in $28.5 \%$ of patients and $60 \%$ of the patient did not develop POPF. One patient developed a bile leak at $2^{\text {nd }}$ postoperative day for which he was re-explored. This patient died on the $4^{\text {th }}$ postoperative day because of the biliary septicemia. One patient had an intra-abdominal hemorrhage and was treated conservatively. Grade A, B, and C delayed gastric emptying (DGE) was noticed in $31.5 \%, 60 \%$, and $8.5 \%$ respectively and the mean-time to start the oral feed was 8.9 days. The 
Table 1. Baseline characteristics of the patients

\begin{tabular}{lc}
\hline \multicolumn{1}{c}{ Characteristics } & Values \\
\hline Age & 53.25 years \\
Sex & \\
$\quad$ Male & $19(53.2 \%)$ \\
$\quad$ Female & $16(46.8 \%)$ \\
ECOG & $29(83 \%)$ \\
I & $6(17 \%)$ \\
II & 9 yeras) \\
Albumin level & $96 \%)$ \\
$\quad<3.5$ gm/dl & $26(74 \%)$ \\
$>3.5$ gm/dl & $29(82.8 \%)$ \\
Icterus & $20(68.6 \%)$ \\
Pre operative biliary diversion & $1(3.4 \%)$ \\
ERCP stenting & $31(88.5 \%)$ \\
PTBD & $3(8.5 \%)$ \\
Diagnosis & $1(2.8 \%)$ \\
Periampullary carcinoma & \\
Head of pancreas carcinoma & \\
Distal cholangio carcinoma &
\end{tabular}

ECOG, eastern cooperative operative group; ERCP, endoscopic retrograde cholangiopancreaticography; PTBD, percutaneous transhepatic biliary drainage
30 days mortality rate was $2.8 \%$. The mean hospital stay was 12.9 days. The details of postoperative morbidity and mortality are described in Table 2. All patients had margin free resection. All patients were sent for adjuvant treatment.

\section{DISCUSSION}

The incidence of postoperative morbidity and mortality after Whipple's procedure largely depends upon the integrity of the pancreatic stump anastomosis. Pancreatic stump reconstruction after pancreaticoduodenectomy was done classically by pancreaticojejunostomy. Walter Kaush initially hypothesized the possibility of Pancreaticogastrostomy in 1912. ${ }^{5}$ Pancreatico-gastrostomy was demonstrated by Waugh and Clagett as a feasible method for pancreatic stump reconstruction in $1946 .{ }^{6}$ The potential advantage of using the stomach instead of jejunum for pancreatic anastomosis is the reduced incidence of the leak because of the inactivation of pancreatic enzymes by the gastric secretion, secondly, the anatomic proximity of the posterior

Table 2. Details of procedures, complications and adverse events

\begin{tabular}{|c|c|}
\hline Characteristics & Values \\
\hline \multicolumn{2}{|l|}{ Procedure } \\
\hline Whipple's procedure & $34(97.1 \%)$ \\
\hline Whipple's with SMV reconstruction & $1(2.8 \%)$ \\
\hline Open Whipple's procedure & $24(68.5 \%)$ \\
\hline Lap assisted & $7(20 \%)$ \\
\hline Lap conversion to open & $4(11.5 \%)$ \\
\hline Roux loop reconstruction & $24(68.5 \%)$ \\
\hline Blood loss & Mean - $635 \mathrm{ml}$ (Range 50-3000 ml) \\
\hline Duration of surgery & Mean - 7.4 hours (Range $4-11$ hours) \\
\hline \multicolumn{2}{|l|}{ Post-operative pancreatic } \\
\hline Grade A & $10(28.5 \%)$ \\
\hline Grade B & $3(8.5 \%)$ \\
\hline Grade C & $1(2.8 \%)$ \\
\hline No POPF & $21(60 \%)$ \\
\hline Post-operative morbidity complications & $22.83 \%$ (Overall) \\
\hline Wound Dehiscence & $2(5.7 \%)$ \\
\hline Intra-peritoneal collection & $4(11.4 \%)$ \\
\hline Post-operative haemorrhage & $1(2.8 \%)$ \\
\hline Bile leak & $1(2.8 \%)$ \\
\hline Days for which pancreatic drain output reached less than $30 \mathrm{ml}$ & Mean 7.22 days (Range 5-12 days) \\
\hline Pancreatic drain removal day & Mean 9 days (Range 6-22 days) \\
\hline Institution of oral sips & Mean 8.82 days (Range $5-22$ days) \\
\hline ICU stay & Mean 4.36 days \\
\hline Hospital stay & 12.9 days (Range $7-26$ days) \\
\hline Post-operative mortality & $1(2.8 \%)$ \\
\hline
\end{tabular}




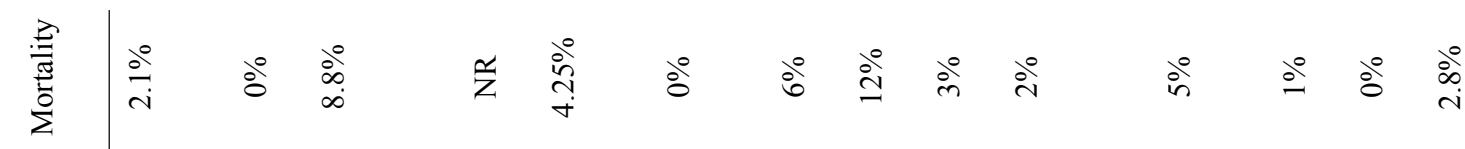

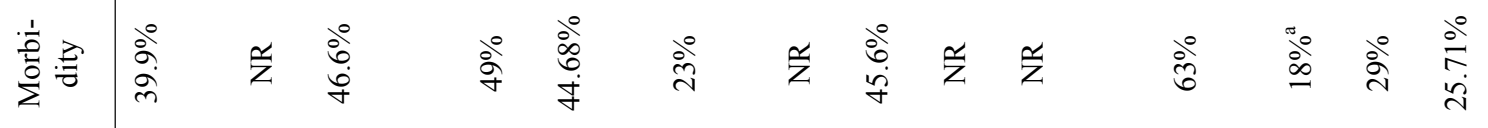

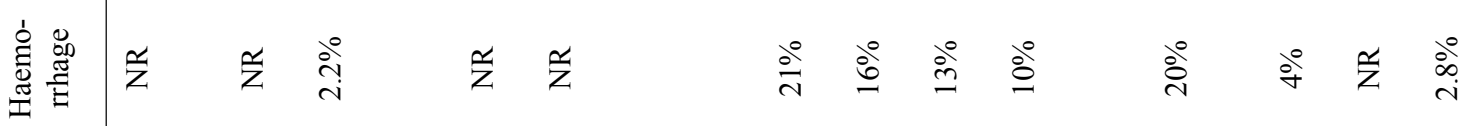

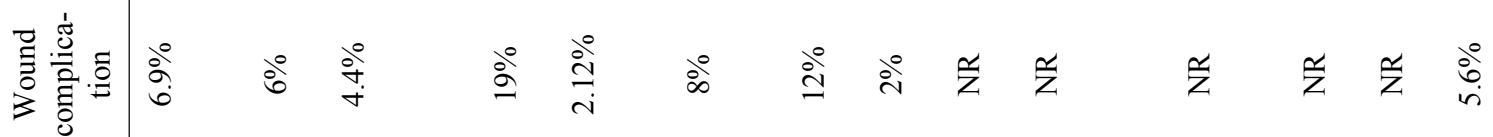
衤

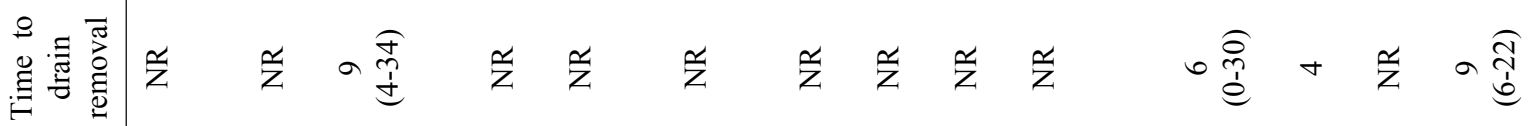

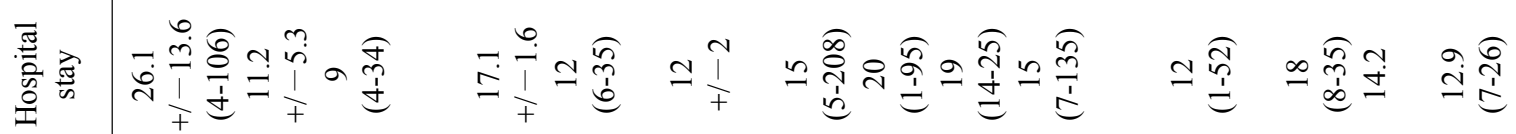

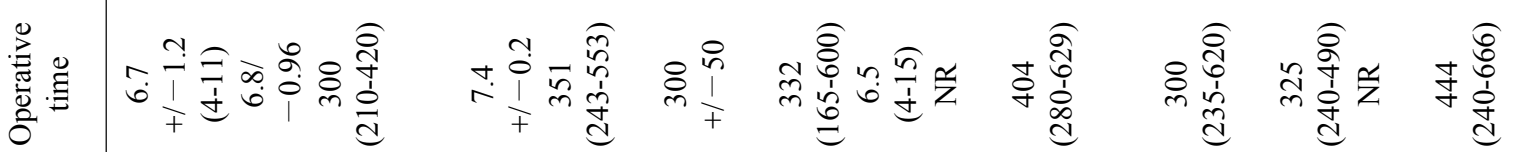

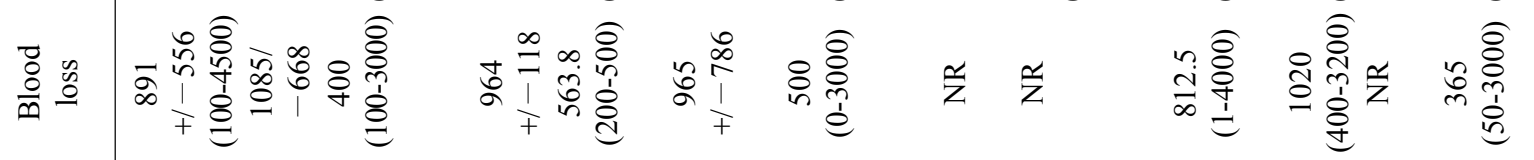

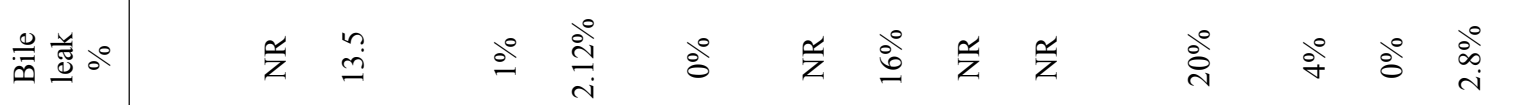

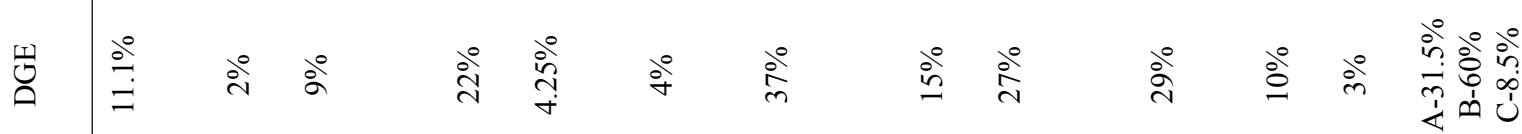

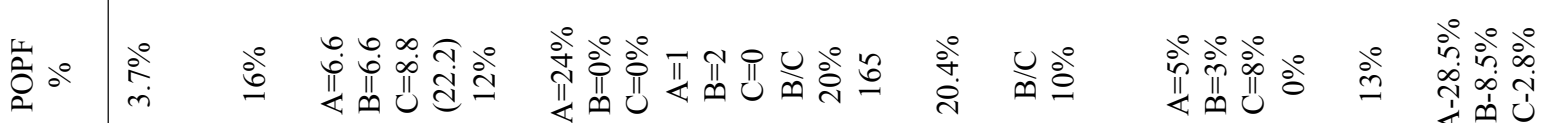

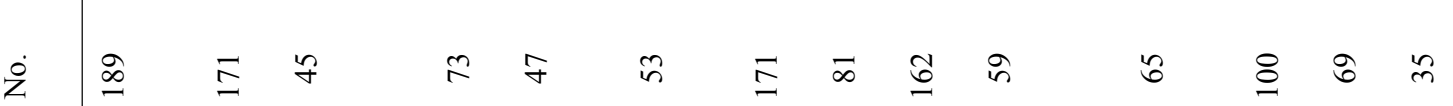

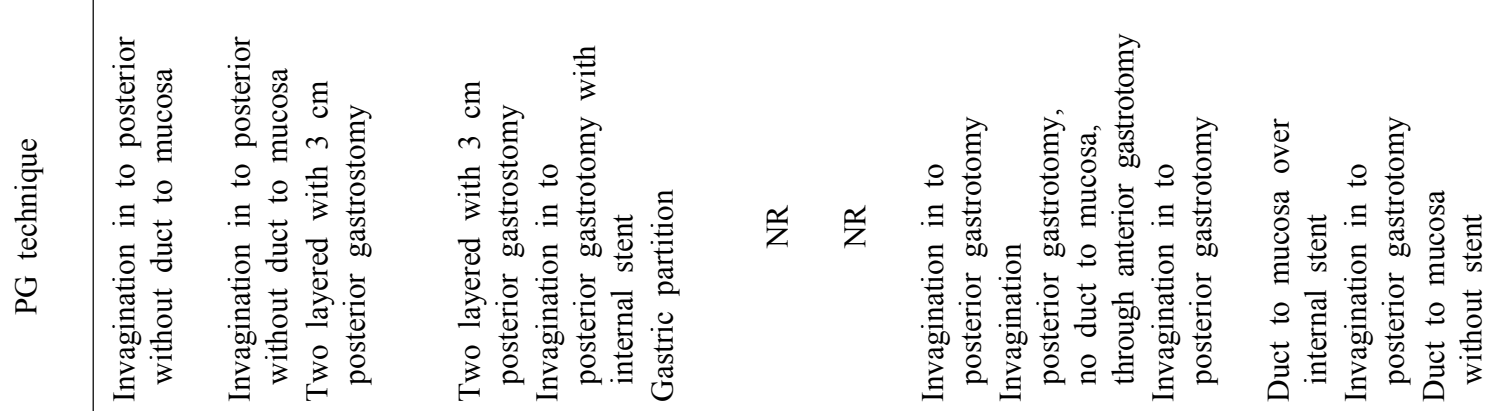

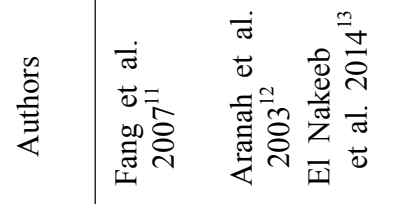

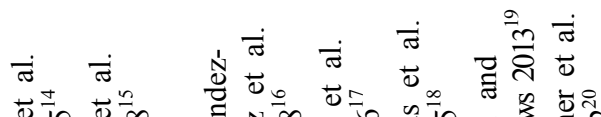


surface of the stomach and pancreatic stump allows a tension free anastomosis and continuous aspiration of pancreatic secretion by nasogastric tube also decreases the pancreatic secretion load and allows less time for auto-digestion. Moreover, the distance of major vessels from the anastomosis can prevent hemorrhage in case of a minor leak of pancreatic enzymes. ${ }^{3}$

Various methods of pancreatico-gastrostomy have been described i.e. Classical PG anastomosis (Waugh and Clagett ${ }^{6}$ ), dunking pancreas with two purse-string sutures (Ohigashi Technique), Montenegro's Technique of Sleeve Gastrectomy, Duct to mucosa technique with internal or external stenting of the pancreatic duct. ${ }^{6-9}$ Oshigashi described a modification in the classical technique of Waugh and Cattell. They propagated the dunking of the pancreatic stump in the posterior wall of the stomach. Another modification of fixing the pancreatic stump into the sleeve of the stomach was proposed by Montenegro. ${ }^{7}$ A comparison of the post-operative outcomes of various methods of pancreaticogastrostomy is shown in Table $3 .^{10-22}$ Among duct to mucosa techniques, the literature describes either posterior gastrotomy and full-thickness suture of pancreatic parenchyma and duct to gastric mucosa or joining of duct to gastric mucosa over a stent. ${ }^{9}$ There are chances of an absence of watertight anastomosis in large gastrotomy sites and hence the occurrence of pancreatic fistula. Our series described the outcomes of two-layered end to side duct to mucosa pancreaticogastrostomy through a small 2-3 $\mathrm{mm}$ posterior gastrotomy without stenting. Cattell and Warren had described a similar technique for two layers duct to mucosa pancreatic anastomosis for jejunum. ${ }^{9}$ None of the published series describes this technique for the stomach without pancreatic duct stent.

In the present series, two-layered duct to mucosa pancreaticogastrostomy with a small gastrotomy of the size of the pancreatic duct and direct anastomoses of the gastric mucosa and pancreatic duct creates a watertight anastomosis, leaving less chance of pancreatic secretion leak into the peritoneal cavity.

To keep the anastomosis patent decompression of the pancreatic duct either by internal or long external stents is described. The retrospective review of Payne et al for outcomes of small gastrotomy duct to mucosa pancreaticogastrostomy did not show POPF. ${ }^{10}$ However, the authors reported the use of internal stents to keep the anasto- mosis patent. Internal stents are passed spontaneously per anum in most of the cases but endoscopic interventions may be required to pull out the retained internal stents. Moreover, proximal migration of the internal stent has also been reported in 5 to $6 \%$ of the patient. ${ }^{23}$ It can lead to bowel obstruction, pancreatitis, and biliary obstruction, bowel perforation, liver abscess, acute cholangitis, abdominal pain, and bezoar ileus. Ortega and colleagues have reported bowel perforation by an internal stent even after 19 years of pancreaticoduodenectomy. ${ }^{24}$ Stent placement carries an inherent possibility of endoscopic intervention in the postoperative period. Our series shows the feasibility and technical compatibility of unstented small gastrotomy pancreaticogastrostomy.

The time taken in performing the anastomosis is less than an hour and it was comparative to another pancreatic anastomosis. Literature reports pancreatic fistula rates up-to $30 \%$ in various studies and techniques. However, in the present series, only one patient had type-C pancreatic fistula as per the current ISGPF definition. Mean hospital stay in our series is comparable to similar studies. However, few of the studies have shown a longer hospital stay (ranged from a minimum of 4 days to a maximum of 208 days) as compared to our study. Fang et al. ${ }^{11}$ and Keck et al. ${ }^{17}$ have a hospital stay range of 4-106 and 5-208 days respectively whereas the current series has a range of 7-26 days. Payne et al performed small incision pancreaticogastrostomy similar to our technique and their hospital stay range is 8-35 days with a mean of 8 days. However, they kept the pancreatic anastomosis stented. The lesser hospital stays in our series may be because almost $90 \%$ of the patient either had no or grade-A POPF and absence of complications of the internal stents. Almost one-third of patients resumed oral diet within 7 days of the surgery whereas $60 \%$ of the patient took up to 2 weeks to resume oral. The morbidity and 30 days mortality rates of the present series are comparable to the other pancreaticogastrostomy studies.

The advantages of the unstented duct to mucosa technique include: 1 easy reproducibility, 2 . lesser time consuming, 3. easy to teach the residents and fellows, 4. has similar comparable postoperative outcomes.

The limitation of our study lies in its retrospective nature and less number of patients.

We would like to conclude that the ideal pancreat- 
icogastrostomy technique is yet to be defined. Unstented duct to mucosa end to side pancreaticogastrostomy by small posterior gastrotomy technique is comparable in outcomes in terms of postoperative pancreatic fistula, morbidity, hospital stay and mortality. This technique avoids postoperative endoscopic interventions and has a potential to replace the pancreaticogastric anastomosis over internal stents. However, to establish the superiority or inferiority of this technique, a larger study is recommended.

\section{ORCID}

Sandeep Kumar Bhoriwal:

https://orcid.org/0000-0002-9184-4254

Sunil Kumar: https://orcid.org/0000-0002-9942-3403

SVS Deo: https://orcid.org/0000-0003-1955-8234

Jyoti Sharma: https://orcid.org/0000-0001-9811-2139

Ashutosh Mishra: https://orcid.org/0000-0002-5390-5482

Naveen Kumar: https://orcid.org/0000-0003-4263-6069

Jyoutishman Saikia: https://orcid.org/0000-0002-3567-6292

Kunal Dhall: https://orcid.org/0000-0003-0884-7401

\section{AUTHOR CONTRIBUTIONS}

Conceptualization: SKB, SK, SD, JS, AM, NK, JYS, KD. Data curation: SKB, SK, JS, AM, NK, JYS, KD. Formal analysis: SKB, SK, SD, JS, AM, NK, JYS, KD. Funding acquisition: Not Required. Methodology: SKB., SK, JS, AM, NK, JYS. Project administration: SKB, SK, SD, JS, AM, JYS, KD. Writing - original draft: SKB, SK, SD, JS, AM, NK, JYS, KD. Writing - review \& editing: SKB, SK, SD, JS, AM, NK, JYS, KD.

\section{REFERENCES}

1. Bray F, Ferlay J, Soerjomataram I, Siegel RL, Torre LA, Jemal A. Global cancer statistics 2018: GLOBOCAN estimates of incidence and mortality worldwide for 36 cancers in 185 countries. CA Cancer J Clin 2018;68:394-424.

2. Rawla P, Barsouk A. Epidemiology of gastric cancer: global trends, risk factors and prevention. Prz Gastroenterol 2019;14: 26-38.

3. Topal B, Fieuws S, Aerts R, Weerts J, Feryn T, Roeyen G, et al. Pancreaticojejunostomy versus pancreaticogastrostomy reconstruction after pancreaticoduodenectomy for pancreatic or periampullary tumours: a multicentre randomised trial. Lancet Oncol 2013;14:655-662.
4. Pulvirenti A, Ramera M, Bassi C. Modifications in the International Study Group for Pancreatic Surgery (ISGPS) definition of postoperative pancreatic fistula. Transl Gastroenterol Hepatol 2017; 2:107.

5. Chan C, Franssen B, Rubio A, Uscanga L. Pancreaticoduodenectomy in a Latin American country: the transition to a high-volume center. J Gastrointest Surg 2008;12:527-533.

6. Waugh JM, Clagett OT. Resection of the duodenum and head of the pancreas for carcinoma; an analysis of thirty cases. Surgery 1946;20:224-232.

7. Costa RM, Lucas L. Ten years experience with 150 pancreaticoduodenectomy with pancreaticoenteric reconstruction using sleeve pancreaticogastrostomy (Montenegro's binding technique). HPB 2016;18:e434.

8. Zhao Y, Zhang J, Lan Z, Jiang Q, Zhang S, Chu Y, et al. Are internal or external pancreatic duct stents the preferred choice for patients undergoing pancreaticoduodenectomy? A meta-analysis. Biomed Res Int 2017;2017:1367238.

9. Langrehr JM, Bahra M, Jacob D, Glanemann M, Neuhaus P. Prospective randomized comparison between a new mattress technique and Cattell (duct-to-mucosa) pancreaticojejunostomy for pancreatic resection. World J Surg 2005;29:1111-1119, discussion 1120-1121.

10. Payne RF, Pain JA. Duct-to-mucosa pancreaticogastrostomy is a safe anastomosis following pancreaticoduodenectomy. $\mathrm{Br} \mathrm{J}$ Surg 2006;93:73-77.

11. Fang WL, Shyr YM, Su CH, Chen TH, Wu CW, Lui WY. Comparison between pancreaticojejunostomy and pancreaticogastrostomy after pancreaticoduodenectomy. J Formos Med Assoc 2007; 106:717-727.

12. Aranha GV, Hodul P, Golts E, Oh D, Pickleman J, Creech S. A comparison of pancreaticogastrostomy and pancreaticojejunostomy following pancreaticoduodenectomy. J Gastrointest Surg 2003;7:672-682.

13. El Nakeeb A, Hamdy E, Sultan AM, Salah T, Askr W, Ezzat $\mathrm{H}$, et al. Isolated Roux loop pancreaticojejunostomy versus pancreaticogastrostomy after pancreaticoduodenectomy: a prospective randomized study. HPB (Oxford) 2014;16:713-722.

14. Yeo CJ, Cameron JL, Maher MM, Sauter PK, Zahurak ML, Talamini MA, et al. A prospective randomized trial of pancreaticogastrostomy versus pancreaticojejunostomy after pancreaticoduodenectomy. Ann Surg 1995;222:580-588; discussion 588-592.

15. Yap PY, Hwang JS, Bong JJ. A modified technique of pancreaticogastrostomy with short internal stent: a single surgeon's experience. Asian J Surg 2018;41:250-256.

16. Fernández-Cruz L, Cosa R, Blanco L, López-Boado MA, Astudillo E. Pancreatogastrostomy with gastric partition after pylorus-preserving pancreatoduodenectomy versus conventional pancreatojejunostomy: a prospective randomized study. Ann Surg 2008;248: 930-938.

17. Keck T, Wellner UF, Bahra M, Klein F, Sick O, Niedergethmann $\mathrm{M}$, et al. Pancreatogastrostomy versus pancreatojejunostomy for RECOnstruction after PANCreatoduodenectomy (RECOPANC, DRKS 00000767): perioperative and long-term results of a multicenter randomized controlled trial. Ann Surg 2016;263:440-449.

18. Duffas JP, Suc B, Msika S, Fourtanier G, Muscari F, Hay JM, et al. A controlled randomized multicenter trial of pancreatogastrostomy or pancreatojejunostomy after pancreatoduodenectomy. Am J Surg 2005;189:720-729.

19. Topal B, Fieuws S. Pancreaticogastrostomy after pancreaticoduodenectomy? Lancet Oncol 2013;14:e340-e341.

20. Wellner UF, Sick O, Olschewski M, Adam U, Hopt UT, Keck T. Randomized controlled single-center trial comparing pancreatogastrostomy versus pancreaticojejunostomy after partial pancreat- 
oduodenectomy. J Gastrointest Surg 2012;16:1686-1695.

21. Figueras J, Sabater L, Planellas P, Muñoz-Forner E, Lopez-Ben $\mathrm{S}$, Falgueras L, et al. Randomized clinical trial of pancreaticogastrostomy versus pancreaticojejunostomy on the rate and severity of pancreatic fistula after pancreaticoduodenectomy. $\mathrm{Br} \mathrm{J}$ Surg 2013;100:1597-1605.

22. Bassi C, Falconi M, Molinari E, Salvia R, Butturini G, Sartori $\mathrm{N}$, et al. Reconstruction by pancreaticojejunostomy versus pancreaticogastrostomy following pancreatectomy: results of a comparative study. Ann Surg 2005;242:767-771; discussion 771-773.
23. Price LH, Brandabur JJ, Kozarek RA, Gluck M, Traverso WL, Irani S. Good stents gone bad: endoscopic treatment of proximally migrated pancreatic duct stents. Gastrointest Endosc 2009; 70:174-179.

24. Ortega PM, Zozaya-Larequi G, Arredondo J, Martí-Cruchaga P, Bellver M, Sánchez-Justicia C, et al. Distal migration of a transanastomotic pancreatic stent resulting in bowel perforation 19 years after pancreatoduodenectomy: report of a case. Surg Today 2015;45:374-377. 